\title{
Association of Homelessness with Hospital Readmissions-an Analysis of Three Large States
}

\author{
Sameed Ahmed M. Khatana, MD, MPH ${ }^{1,2,3}$, Rishi K. Wadhera, MD, MPP, MPhil ${ }^{4,5,6}$, \\ Eunhee Choi, PhD 4,5,6, Peter W. Groeneveld, MD, MS ${ }^{2,3,7,8}$, Dennis P. Culhane, PhD', \\ Margot Kushel, MD ${ }^{10}$, Dhruv S. Kazi, MD, MS ${ }^{4,5,6}$, Robert W. Yeh, MD, MSc ${ }^{4,5,6}$, and \\ Changyu Shen, $\mathrm{PhD}^{4,5,6}$
}

\begin{abstract}
'Division of Cardiovascular Medicine, Perelman School of Medicine, University of Pennsylvania, 3400 Civic Center Boulevard, Philadelphia, PA, USA; ${ }^{2}$ Penn Cardiovascular Outcomes, Quality, \& Evaluative Research Center, Perelman School of Medicine, University of Pennsylvania, Philadelphia, PA, USA; ${ }^{3}$ The Leonard Davis Institute of Health Economics, University of Pennsylvania, Philadelphia, PA, USA; ${ }^{4}$ Richard A. and Susan F. Smith Center for Outcomes Research in Cardiology, Beth Israel Deaconess Medical Center, Boston, MA, USA; ${ }^{5}$ Division of Cardiology, Beth Israel Deaconess Medical Center, Boston, MA, USA; ${ }^{6} \mathrm{Harvard}$ Medical School, Boston, MA, USA; 'Division of General Internal Medicine, Perelman School of Medicine, University of Pennsylvania, Philadelphia, PA, USA; ${ }^{8}$ Center for Health Equity Research and Promotion, Michael J. Crescenz Veterans Affairs Medical Center, Philadelphia, PA, USA; ${ }^{9}$ School of Social Policy \& Practice, University of Pennsylvania, Philadelphia, PA, USA; ${ }^{10}$ Division of General Internal Medicine at San Francisco General Hospital, University of California, San Francisco, San Francisco, CA, USA.
\end{abstract}

BACKGROUND: Individuals experiencing homelessness have higher hospitalization and mortality rates compared with the housed. Whether they also experience higher readmission rates, and if readmissions vary by region or cause of hospitalization is unknown.

OBJECTIVE: Evaluate the association of homelessness with readmission rates across multiple US states.

DESIGN: Retrospective analysis of administrative claims PATIENTS: All inpatient hospitalizations in Florida, Massachusetts, and New York from January 2010 to October 2015

MAIN MEASURES: Thirty- and 90-day readmission rates KEY RESULTS: Out of a total of 23, 103,125 index hospitalizations, 515,737 were for patients who were identified as homeless at the time of discharge. After adjusting for cause of index hospitalization, state, demographics, and clinical comorbidities, 30-day and 90-day readmission rates were higher for index hospitalizations in the homeless compared with those in the housed group. The difference in 30-day readmission rates between homeless and housed groups was the largest in Florida (30.4\% vs. $19.3 \% ; p<0.001)$, followed by Massachusetts (23.5\% vs. $15.2 \% ; p<0.001)$ and New York (15.7\% vs. $13.4 \%$; $p<$ 0.001 ) (combined $17.3 \%$ vs. $14.0 \% ; p<0.001$ ). Among the most common causes of hospitalization, 30-day readmission rates were 4.1 percentage points higher for the homeless group for mental illness, 4.9 percentage points higher for diseases of the circulatory system, and 2.4 percentage points higher for diseases of the digestive system.

CONCLUSIONS: After adjusting for demographic and clinical characteristics, homelessness is associated with significantly higher 30- and 90-day readmission rates, with a significant variation across the three states.

Electronic supplementary material The online version of this article (https://doi.org/10.1007/s11606-020-05946-4) contains supplementary material, which is available to authorized users.

Received October 25, 2019

Accepted May 28, 2020

Published online June 17, 2020
Interventions to reduce the burden of readmissions among individuals experiencing homelessness are urgently needed. Differences across states point to the potential of certain public policies to impact health outcomes for individuals experiencing homelessness.

J Gen Intern Med 35(9):2576-83

DOI: $10.1007 / \mathrm{s} 11606-020-05946-4$

(c) Society of General Internal Medicine 2020

\section{INTRODUCTION}

Homelessness affects a large number of Americans, and recent evidence suggests that homelessness is increasing in the USA. ${ }^{1}$ One in 67 Americans will experience homelessness in any given year, and one in 25 will experience it at least once during their lifetime. ${ }^{2}$ Individuals who are homeless represent an especially medically vulnerable population, with mortality rates that are significantly higher than the general population. ${ }^{3}$ This is related to a greater burden of disease, including chronic diseases, mental illness, and substance use disorders, as well as the financial and structural barriers that impede access to appropriate care. $^{4-8}$

In recent years, federal funding to improve access and delivery of health care to the homeless population has doubled in the USA. ${ }^{9}$ Despite this, homeless individuals continue to have higher rates of hospitalizations for acute illness, with recent data showing that their hospitalization rates have increased 20 to $50 \%$ across multiple states in the last decade. ${ }^{10}$, ${ }^{11}$ Given the many barriers that homeless individuals face in accessing follow-up care, it is likely that they also experience higher rates of readmissions. Prior studies suggest that homeless individuals may experience higher rates of readmission after an index hospitalization. ${ }^{12-14}$ However, these studies have been limited by a relatively small sample size of patients 
experiencing homelessness or have only evaluated certain medical conditions or procedures.

Understanding whether homelessness is associated with higher rates of readmission, and the magnitude of difference compared with the general population, is important from both a public health and policy perspective. Characterizing readmissions among homeless individuals will help inform both local and state initiatives that aim to enhance access to ambulatory care and improve care coordination for this population in the vulnerable period immediately following hospitalization. Public policies that may have significant impacts on the health of homeless individuals, such as Medicaid eligibility criteria or right to shelter laws, also vary across states. However, it is unclear how health outcomes such as hospital readmissions vary across regions. Additionally, unplanned readmissions have become an important marker for hospital care delivery and quality, often tied to financial incentives and penalty programs. ${ }^{15}$ As homeless individuals typically receive inpatient care at safety net hospitals, higher readmission rates among homeless patients may result in disproportionate penalties being levied on these hospitals, which could potentially widen disparities in care.

We used administrative claims data from three large, geographically diverse states with large homeless populations - Florida, Massachusetts, and New York. These three states were collectively home to $26 \%$ of the homeless population in the country in 2015 (16\% in New York, 6\% in Florida, and $4 \%$ in Massachusetts). ${ }^{16}$ We used these data to evaluate whether homelessness is associated with a differential risk of 30- and 90-day readmission rates after an index hospitalization. Additionally, we investigated whether the risk of readmission differs based on location and cause of the index hospitalization.

\section{METHODS}

\section{Data Source}

We used the State Inpatient Databases (SIDs) provided by the Agency for Healthcare Research and Quality Healthcare (AHRQ) Healthcare Cost and Utilization Project. ${ }^{17}$ The SIDs contain discharge information from non-federal acute care hospitals and certain specialty facilities based on administrative claims data. They include patient demographics, clinical diagnoses, and expected payer. The three included states all provide a patient label that allows identification of multiple hospitalizations from the same subject as well as an indicator of homelessness status at the time of discharge. For these states, we included all inpatient discharges from January 1, 2010, through September 30, 2015. As the analysis only utilizes publicly available de-identified data, Institutional Review Board review was not required based on guidelines from the Beth Israel Deaconess Medical Center Committee on Clinical Investigations. All cells with fewer than 10 individuals were suppressed from the data tables presented in this analysis.

\section{Study Population}

The overall study population included all individuals 18 years of age and older who had at least one inpatient hospitalization and survived until discharge. We defined hospitalizations among homeless individuals as those where the patient was noted to be homeless at the time of discharge from their index hospitalization and are referred to as the homeless group. The remainder were considered hospitalizations among housed individuals and are referred to as the housed group. We identified the homelessness status by the homeless indicator that is used by the AHRQ and has also been used in prior analyses. ${ }^{11,18-21}$ For the purpose of this analysis, a readmission was defined as the first hospitalization within 30 or 90 days of discharge (readmissions within 90 days include readmissions within 30 days of discharge from index hospitalization). Hospitalizations occurring more than 30 or 90 days after discharge were counted as another index hospitalization.

After identifying the homeless and housed groups of hospitalizations, we matched the two groups based on the following attributes: age (in 5-year intervals), gender (male vs. female), race/ethnicity (White, Black, Hispanic, or other), state of hospitalization, and cause of index admission by clinical classification of diseases (CCS) category, ${ }^{22}$ and the presence of 22 clinical comorbidities: deficiency anemias, rheumatoid arthritis/collagen vascular diseases, anemia from chronic blood loss, congestive heart failure, chronic pulmonary disease, coagulation disorders, diabetes, diabetes with chronic complications, hypertension, hypothyroidism, lymphoma, fluid and electrolyte disorders, metastatic cancer, neurologic disorders, paralysis, peripheral vascular disorders, pulmonary circulation disorders, renal failure, solid tumor without metastases, peptic ulcer disease, valvular disease, and weight loss. These comorbidities were adopted from the Elixhauser comorbidity index. ${ }^{23}$ Since Massachusetts did not include mental illness and substance abuse comorbidities, these were not included in the adjustment. The included attributes were used to create strata where there was at least one hospitalization for a homeless individual and one hospitalization by a housed individual in each stratum. The comparison based on matching, referred to as the adjusted analysis, eliminates the potential confounding effect of the variables used for matching. Strata without any hospitalization from the homeless group were removed. Each stratum received a relative weight based on the proportion of hospitalizations from the homeless group in it.

\section{Statistical Analysis}

Summary statistics are presented as mean and standard deviation or counts and percentages, unless indicated otherwise. We first compared demographics, health insurance payor status for index hospitalization, clinical comorbidities, and rates 
of 30-day and 90-day readmissions between the homeless and housed groups. After adjusting for the previously mentioned attributes, we computed the difference of the 30-day and 90 day readmission rates between the homeless and housed groups within each stratum, and aggregated the differences using each stratum's relative size (e.g., proportion) in the homeless group. We also ranked the cause of index hospitalizations (by CCS group) by the number of index hospitalizations for each cause in the homeless group. We then compared the 30-day and 90-day readmission rates between homeless and housed individuals for each of the top 4 most common causes of index hospitalization separately. We evaluated each of the three states separately as well as analyzing all of the data combined. $p$ values $<0.05$ were considered statistically significant. Analyses were performed using SAS (SAS Institute Inc., Cary, NC) version 9.4.

\section{RESULTS}

Of a total of $23,103,125$ index hospitalizations during the study period, 515,737 hospitalizations occurred among patients noted to be homeless at the time of discharge (Table 1). Of these, 40,212 were in Florida, 28,089 were in Massachusetts, and 447,436 were in New York. In the homeless group, the patients were younger and had a lower diagnosed prevalence of all 22 comorbidities that were included in the adjusted analysis. Compared with the housed group, hospitalizations with homeless individuals had a higher percentage of individuals who were male ( $45.28 \%$ vs. $41.37 \%)$, Black (33.6\% vs. $14.9 \%$ ), or Hispanic ( $24.9 \%$ vs. $12.8 \%$ ). A greater percentage of hospitalizations for homeless individuals were for Medicaid beneficiaries (65.9\% vs. $17.3 \%$ ) or the uninsured (7.7\% vs. $4.5 \%)$. In unadjusted analyses, $17.7 \%$ of index hospitalizations for the homeless group resulted in a readmission within 30 days vs. $15.1 \%$ for the housed group. At 90 days, readmission rates were $24.5 \%$ and $22.0 \%$ for the homeless and housed groups, respectively.

Using age, demographics, state, cause of hospitalization, and clinical comorbidities, we obtained 92,166 unique strata such that there was at least one homeless hospitalization and one housed hospitalization in each stratum. The adjusted analysis showed that the 30-day and 90-day readmission rates

Table 1 Readmission Rates, Demographics, and Comorbidities

\begin{tabular}{|c|c|c|c|c|c|c|c|c|}
\hline & \multicolumn{2}{|l|}{ Florida } & \multicolumn{2}{|c|}{ Massachusetts } & \multicolumn{2}{|l|}{ New York } & \multicolumn{2}{|l|}{ Combined } \\
\hline & Homeless & Housed & Homeless & Housed & Homeless & Housed & Homeless & Housed \\
\hline Number of index hospitalizations & 40,212 & $10,580,959$ & 28,089 & $2,676,526$ & 447,436 & $9,329,903$ & 515,737 & $22,587,388$ \\
\hline Readmitted in 30 days $(\%)$ & 30.6 & 16.0 & 23.8 & 14.1 & 16.2 & 14.5 & 17.7 & 15.1 \\
\hline Readmitted in 90 days (\%) & 39.6 & 23.0 & 35.5 & 21.4 & 22.7 & 21.0 & 24.5 & 22.0 \\
\hline Age, mean (SD) (years) & $\begin{array}{l}46.8 \\
(12.6)\end{array}$ & $58.8(20.6)$ & $\begin{array}{l}45.8 \\
(14.5)\end{array}$ & $\begin{array}{l}59.1 \\
(20.6)\end{array}$ & $\begin{array}{l}47.8 \\
(19.5)\end{array}$ & $\begin{array}{l}56.8 \\
(21.0)\end{array}$ & $\begin{array}{l}47.6 \\
(18.8)\end{array}$ & $58.0(20.8)$ \\
\hline Male (\%) & 77.7 & 41.9 & 69.7 & 41.4 & 40.8 & 40.7 & 45.3 & 41.4 \\
\hline \multicolumn{9}{|l|}{ Race } \\
\hline White (\%) & 66.4 & 66.9 & 68.8 & 81.7 & 11.2 & 59.0 & 18.6 & 65.4 \\
\hline Black $(\%)$ & 19.6 & 15.8 & 16.5 & 7.1 & 35.9 & 16.2 & 33.6 & 14.9 \\
\hline Hispanic (\%) & 12.4 & 14.9 & 12.8 & 7.7 & 26.8 & 11.8 & 24.9 & 12.8 \\
\hline \multicolumn{9}{|l|}{ Payor } \\
\hline Medicare (\%) & 19.6 & 51.2 & 28.6 & 49.6 & 22.3 & 42.3 & 22.5 & 47.3 \\
\hline Medicaid (\%) & 22.1 & 14.6 & 50.2 & 13.6 & 70.8 & 21.4 & 65.9 & 17.3 \\
\hline Private insurance $(\%)$ & 4.5 & 22.7 & 11.3 & 31.6 & 1.2 & 30.3 & 2.0 & 26.9 \\
\hline Uninsured/self-pay (\%) & 37.3 & 6.3 & 1.2 & 0.7 & 5.4 & 3.5 & 7.7 & 4.5 \\
\hline \multicolumn{9}{|l|}{ Comorbidities } \\
\hline Hypertension (\%) & 32.8 & 52.2 & 30.7 & 46.8 & 37.6 & 46.7 & 36.9 & 49.3 \\
\hline Diabetes without chronic & 9.2 & 19.3 & 10.5 & 16.1 & 18.0 & 17.8 & 16.9 & 18.3 \\
\hline complications $(\%)$ & & & & & & & & \\
\hline $\begin{array}{l}\text { Diabetes with chronic } \\
\text { complications }(\%)\end{array}$ & 1.7 & 3.9 & 2.9 & 4.0 & 3.2 & 3.4 & 3.1 & 3.7 \\
\hline Congestive heart failure (\%) & 1.7 & 6.3 & 3.6 & 7.8 & 4.0 & 6.7 & 3.8 & 6.6 \\
\hline Chronic pulmonary disease $(\%)$ & 16.1 & 17.4 & 20.8 & 18.1 & 13.2 & 16.3 & 13.9 & 17.0 \\
\hline Pulmonary circulation disorders & 0.5 & 1.8 & 0.8 & 1.7 & 0.9 & 1.6 & 0.9 & 1.7 \\
\hline Lymphoma & 0.1 & 0.7 & 0.3 & 0.9 & 0.3 & 0.7 & 0.3 & 0.7 \\
\hline Solid tumor without metastasis $(\%)$ & 0.5 & 1.7 & 0.9 & 1.9 & 1.3 & 1.8 & 1.2 & 1.8 \\
\hline Metastatic cancer $(\%)$ & 0.3 & 1.7 & 0.5 & 2.2 & 1.1 & 2.1 & 1.0 & 1.9 \\
\hline Blood loss anemia (\%) & 0.5 & 2.1 & 0.6 & 1.8 & 3.2 & 2.1 & 2.8 & 2.1 \\
\hline Deficiency anemias (\%) & 11.6 & 18.1 & 8.5 & 12.5 & 11.6 & 12.7 & 11.5 & 15.2 \\
\hline Coagulation deficiency $(\%)$ & 6.4 & 4.7 & 5.5 & 3.9 & 3.1 & 3.8 & 3.5 & 4.2 \\
\hline $\begin{array}{l}\text { Rheumatoid arthritis/collagen vas- } \\
\text { cular diseases }(\%)\end{array}$ & 0.6 & 2.7 & 1.1 & 2.9 & 1.1 & 2.3 & 1.0 & 2.5 \\
\hline Hypothyroidism $(\%)$ & 2.9 & 11.6 & 3.6 & 10.9 & 4.5 & 10.1 & 4.3 & 10.9 \\
\hline Fluid and electrolyte disorders $(\%)$ & 20.5 & 22.1 & 18.2 & 20.0 & 12.8 & 18.0 & 13.7 & 20.2 \\
\hline Paralysis $(\%)$ & 1.0 & 1.9 & 1.1 & 1.8 & 1.8 & 2.0 & 1.7 & 1.9 \\
\hline Other neurological disorders $(\%)$ & 10.2 & 7.1 & 9.4 & 7.0 & 5.8 & 6.4 & 6.4 & 6.8 \\
\hline Valvular disease $(\%)$ & 0.9 & 3.9 & 1.2 & 3.6 & 1.1 & 3.4 & 1.1 & 3.7 \\
\hline Peripheral vascular disease $(\%)$ & 1.8 & 6.0 & 1.9 & 5.1 & 1.8 & 4.3 & 1.8 & 5.2 \\
\hline Renal failure $(\%)$ & 2.6 & 10.8 & 4.2 & 10.7 & 6.5 & 9.4 & 6.0 & 10.2 \\
\hline Weight loss (\%) & 3.1 & 3.3 & 3.1 & 2.8 & 2.1 & 2.7 & 2.2 & 3.0 \\
\hline
\end{tabular}


were higher for index hospitalizations in the homeless group compared with those in the housed group (17.3\% (SE $=0.04)$ vs. $14.0 \%(\mathrm{SE}=0.02), p<0.001$; and $23.8 \%(\mathrm{SE}=0.05)$ vs. $19.9 \%$ (SE $=0.02), p<0.001$, respectively) (Fig. 1 and Supplement Table 1). However, there was a significant variation across the three states. The largest difference in 30-day readmission rates between the homeless and housed groups was in Florida (30.4\% ( $\mathrm{SE}=0.02)$ vs. $19.3 \%(\mathrm{SE}=0.003) ; p<$ $0.001)$ followed by Massachusetts $(23.5 \%$ ( $\mathrm{SE}=0.01)$ vs. $15.2 \%(\mathrm{SE}=0.003) ; p<0.001)$ and New York $(15.7 \%$ (SE $=0.04)$ vs. $13.4 \%(\mathrm{SE}=0.02) ; p<0.001)$. A similar trend was observed for 90 -day readmissions.

The four most common causes for index hospitalizations in the homeless group were mental illness, complications of pregnancy childbirth and the puerperium, diseases of the circulatory system, and diseases of the digestive system (Table 2). Differences in readmission rates after hospitalizations between the homeless and housed groups for each of the abovementioned causes of index hospitalization are shown in Figure 2 and Supplement Table 2. Thirty-day readmission rates were 4.1 percentage points higher $(p<0.001)$ for the homeless group where mental illness was the index cause of hospitalization, 4.9 percentage points higher $(p<0.001)$ for diseases of the circulatory system, and 2.4 percentage points higher $(p<0.001)$ for diseases of the digestive system. Thirtyday readmission rates where the cause of index hospitalization was for complications of pregnancy, childbirth, and the puerperium were 0.2 percentage points lower $(p=0.01)$ in the homeless group. Similar trends were seen for 90 -day readmission rates. There were substantial differences across states in these trends with a greater difference between the two groups seen in Florida, followed by Massachusetts and New York (Supplement Table 2). Notably, 30-day readmission rates for the homeless group for complications of pregnancy were 2.9 percentage points higher compared with those for the housed group ( $p=0.002)$ in Florida, 0.2 percentage points lower $(p<$ 0.001 ) in New York, and not statistically different in
Massachusetts.

\section{DISCUSSION}

In this study of administrative claims data from Florida, Massachusetts, and New York from 2010 to 2015, we found that hospitalizations for patients who were homeless at the time of discharge resulted in significantly higher $30-$ and 90 -day readmission rates compared with hospitalizations for housed individuals. In addition, there was a significant variation across states, with the largest disparities in readmission rates between homeless and housed patients seen in Florida, followed by Massachusetts and New York.

This is the first large study to examine the association of homelessness with hospital readmissions across multiple US states and for all conditions. Our work builds on the findings of prior studies that noted higher readmission rates in homeless individuals. One study of 1165 homeless patients from a hospital in Toronto, Ontario, revealed a 30-day readmission rate of $22 \%$, compared with a rate of $7 \%$ in a matched cohort of non-homeless patients. ${ }^{12}$ A study of 331 homeless individuals in Harris County, TX, revealed a threefold higher rate of 30-day readmissions compared with housed individuals. ${ }^{13}$ Another recent study of veterans discharged from the hospital after surgical procedures, which included 5068 homeless patients, found a $43 \%$ higher odds of readmission to the hospital associated with homelessness. ${ }^{14}$ We observed a smaller absolute difference in the readmission rates between the homeless and housed groups compared with some of these prior studies. Although differences in the definition of homelessness, statistical methods, and smaller sample sizes of those studies make direct comparisons difficult, our findings are concordant in that they demonstrated a significantly higher readmission rate associated with homelessness. The high burden of readmissions in this population is particularly highlighted by the fact that despite being younger and having fewer

Thirty- and 90-day readmission rates by homelessness status (adjusted analysis)

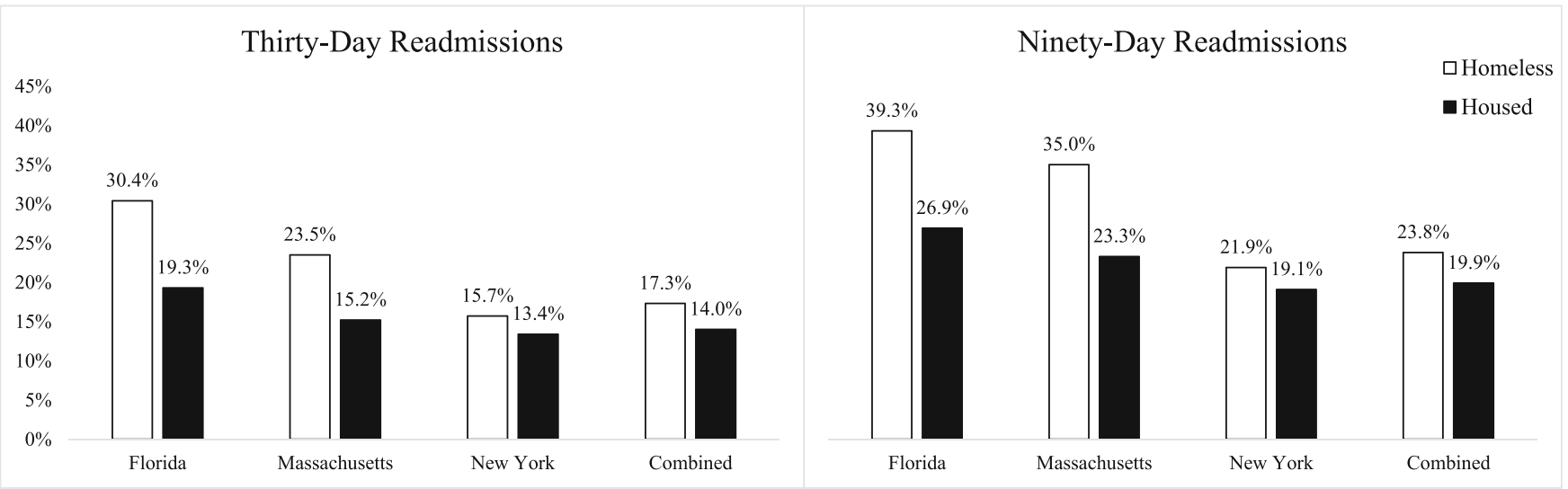

Figure 1 Adjusted for age, demographics, gender, race/ethnicity, state, cause of index hospitalization by clinical classification of diseases (CCS) category, and presence of 22 clinical comorbidities. Error bars omitted due to small standard errors 
Table 2 Number of Index Hospitalizations by Cause of Hospitalization in the Homeless Group

\begin{tabular}{|c|c|c|c|c|c|c|c|c|c|}
\hline \multicolumn{5}{|c|}{ 30-day readmissions } & \multicolumn{5}{|c|}{ 90-day readmissions } \\
\hline $\begin{array}{l}\text { Cause of index } \\
\text { hospitalization }\end{array}$ & Florida & Massachusetts & $\begin{array}{l}\text { New } \\
\text { York }\end{array}$ & Combined & $\begin{array}{l}\text { Cause of index } \\
\text { hospitalization }\end{array}$ & Florida & Massachusetts & $\begin{array}{l}\text { New } \\
\text { York }\end{array}$ & Combined \\
\hline Mental illness & 20,188 & 12,344 & 83,192 & 115,724 & Mental illness & 15,503 & 9,834 & 69,177 & 94,514 \\
\hline $\begin{array}{l}\text { Complications of } \\
\text { pregnancy } \\
\text { childbirth and the } \\
\text { puerperium }\end{array}$ & 153 & 730 & 91,837 & 92,720 & $\begin{array}{l}\text { Complications of } \\
\text { pregnancy } \\
\text { childbirth and the } \\
\text { puerperium }\end{array}$ & 143 & 679 & 89,378 & 90,200 \\
\hline $\begin{array}{l}\text { Diseases of the } \\
\text { circulatory system }\end{array}$ & 3709 & 2012 & 56,194 & 61,915 & $\begin{array}{l}\text { Diseases of the } \\
\text { circulatory system }\end{array}$ & 2958 & 1570 & 49,170 & 53,698 \\
\hline $\begin{array}{l}\text { Diseases of the } \\
\text { digestive system }\end{array}$ & 2260 & 1590 & 32,435 & 36,285 & $\begin{array}{l}\text { Diseases of the } \\
\text { digestive system }\end{array}$ & 1812 & 1254 & 28,969 & 32,035 \\
\hline $\begin{array}{l}\text { Diseases of the } \\
\text { respiratory system }\end{array}$ & 2323 & 2006 & 28,404 & 32,733 & $\begin{array}{l}\text { Injury and } \\
\text { poisoning }\end{array}$ & 2770 & 1750 & 24,025 & 28,545 \\
\hline $\begin{array}{l}\text { Injury and } \\
\text { poisoning }\end{array}$ & 3185 & 2137 & 26,747 & 32,069 & $\begin{array}{l}\text { Diseases of the } \\
\text { respiratory system }\end{array}$ & 1858 & 1518 & 24,308 & 27,684 \\
\hline $\begin{array}{l}\text { Endocrine } \\
\text { nutritional and } \\
\text { metabolic disease } \\
\text { and immunity } \\
\text { disorders }\end{array}$ & 1203 & 794 & 20,049 & 22,046 & $\begin{array}{l}\text { Endocrine } \\
\text { nutritional and } \\
\text { metabolic disease } \\
\text { and immunity } \\
\text { disorders }\end{array}$ & 915 & 601 & 17,467 & 18,983 \\
\hline $\begin{array}{l}\text { Diseases of the } \\
\text { genitourinary } \\
\text { system }\end{array}$ & 762 & 575 & 14,261 & 15,598 & $\begin{array}{l}\text { Diseases of the } \\
\text { genitourinary } \\
\text { system }\end{array}$ & 629 & 471 & 12,601 & 13,701 \\
\hline Neoplasms & 282 & 388 & 13,984 & 14,654 & Neoplasms & 233 & 334 & 11,918 & 12,485 \\
\hline $\begin{array}{l}\text { Diseases of the } \\
\text { nervous system } \\
\text { and sense organs }\end{array}$ & 981 & 626 & 12,258 & 13,865 & $\begin{array}{l}\text { Diseases of the } \\
\text { nervous system } \\
\text { and sense organs }\end{array}$ & 782 & 498 & 10,764 & 12,044 \\
\hline $\begin{array}{l}\text { Infectious and } \\
\text { parasitic disease }\end{array}$ & 890 & 790 & 10,248 & 11,928 & $\begin{array}{l}\text { Infectious and } \\
\text { parasitic disease }\end{array}$ & 731 & 607 & 8693 & 10,031 \\
\hline $\begin{array}{l}\text { Diseases of the } \\
\text { skin and } \\
\text { subcutaneous } \\
\text { tissue }\end{array}$ & 1793 & 1162 & 7537 & 10,492 & $\begin{array}{l}\text { Diseases of the } \\
\text { skin and } \\
\text { subcutaneous } \\
\text { tissue }\end{array}$ & 1494 & 975 & 6695 & 9164 \\
\hline $\begin{array}{l}\text { Diseases of the } \\
\text { musculoskeletal } \\
\text { system and } \\
\text { connective tissue }\end{array}$ & 649 & 613 & 8857 & 10,119 & $\begin{array}{l}\text { Diseases of the } \\
\text { musculoskeletal } \\
\text { system and } \\
\text { connective tissue }\end{array}$ & 516 & 540 & 8055 & 9111 \\
\hline $\begin{array}{l}\text { Symptoms, signs, } \\
\text { and ill-defined } \\
\text { conditions and } \\
\text { factors influenc- } \\
\text { ing health status }\end{array}$ & 532 & 283 & 9083 & 9898 & $\begin{array}{l}\text { Symptoms, signs, } \\
\text { and ill-defined } \\
\text { conditions and } \\
\text { factors influenc- } \\
\text { ing health status }\end{array}$ & 446 & 216 & 8084 & 8746 \\
\hline $\begin{array}{l}\text { Diseases of the } \\
\text { blood and blood- } \\
\text { forming organs }\end{array}$ & 192 & 131 & 6762 & 7085 & $\begin{array}{l}\text { Diseases of the } \\
\text { blood and blood- } \\
\text { forming organs }\end{array}$ & 154 & 87 & 5374 & 5615 \\
\hline Unclassified & 101 & 41 & 1331 & 1473 & Unclassified & 83 & 34 & 1126 & 1243 \\
\hline
\end{tabular}

diagnosed comorbidities than housed individuals, homeless individuals were still more likely to be readmitted to the hospital.

We noted substantial differences in readmission rates across the three states. Disparities in readmission rates between homeless and housed groups were substantial in Florida, and much smaller in New York. It is likely that this variation, at least in part, reflects differences in state policies and programs that target this population. One notable difference among the three states has been the expansion of Medicaid eligibility under the Affordable Care Act, with Massachusetts and New York have expanded Medicaid eligibility while Florida has not. ${ }^{24}$ Medicaid expansion has been associated with a significant increase in the proportion of homeless individuals with health insurance coverage. Although few studies have examined the impact of Medicaid expansion on the health outcomes of homeless individuals, in one prior study, fewer discharges from hospitalizations against medical advice, and greater receipt of outpatient services were noted for homeless individuals living in states that expanded Medicaid compared with those living in non-expansion states. ${ }^{20}$ Greater access to primary care and care coordination through Medicaid may therefore be responsible for improvements in care received in the post-hospitalization period, and potentially lower readmission rates. Importantly, Medicaid expansion has also been associated with improvements in access to substance abuse treatments and mental health treatments, ${ }^{25}$ which may have a significant impact on readmissions given that mental illness was the most common cause of index hospitalizations leading to readmissions in our analysis. Interstate variation in readmission rates may also at least partly be related to the resources available for people who experience homelessness. The proportion of homeless individuals without shelter (a marker of the scarcity of resources available to homeless individuals) is substantially higher in Florida (47\%) than in Massachusetts $(3 \%)$ and New York (5\%). ${ }^{26}$ This is likely a reflection of 
Thirty-day readmission rates by cause of index hospitalization status (adjusted analysis)

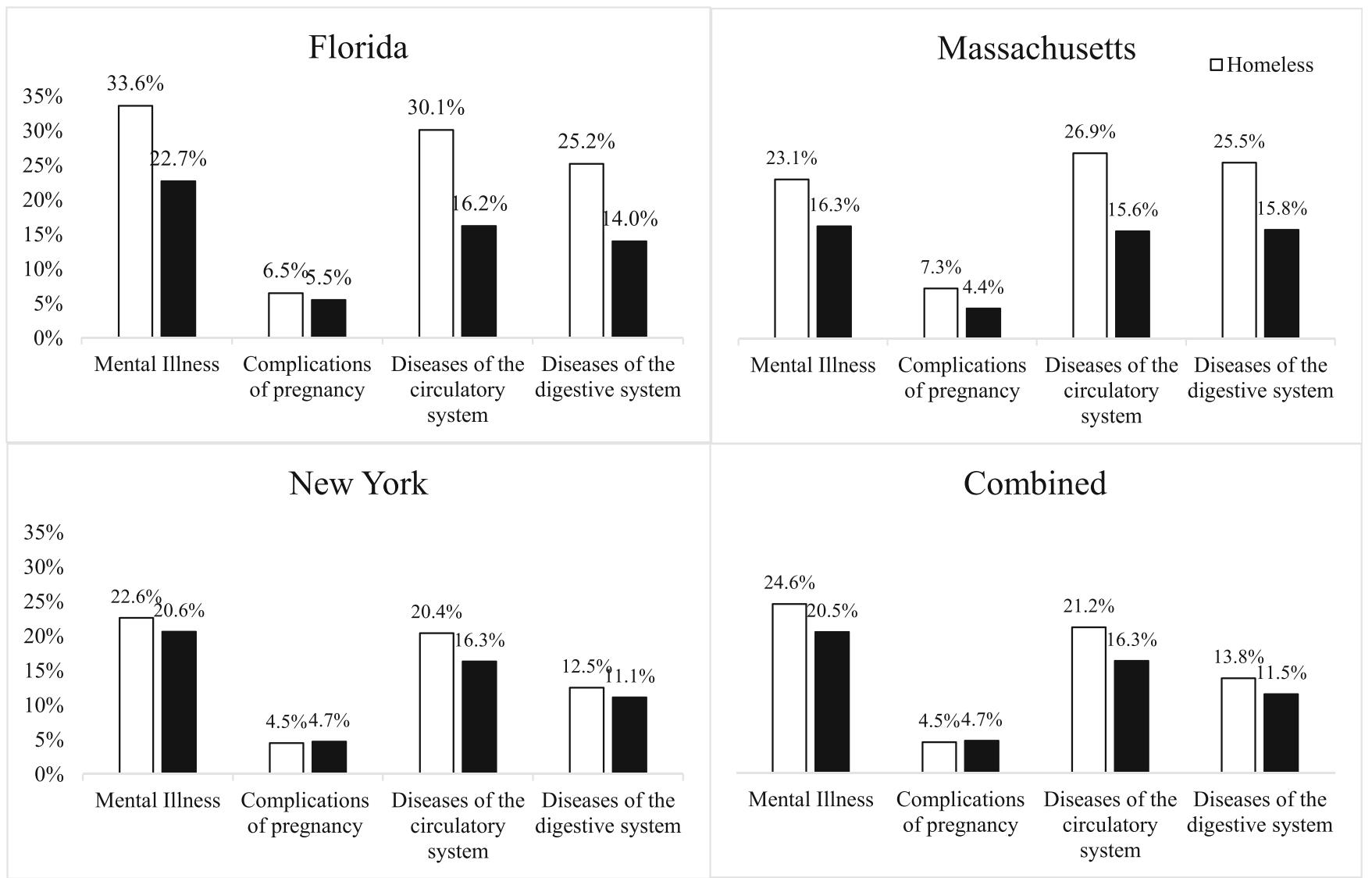

Figure 2 adjusted for age, demographics, gender, race/ethnicity, state, cause of index hospitalization by clinical classification of diseases (CCS) category, and presence of 22 clinical comorbidities. Error bars omitted due to small standard errors

certain state and local policies. New York City, where the majority of homeless individuals in the state reside, has a court-mandated policy to provide shelter to all homeless individuals in the city. ${ }^{27}$ Massachusetts has a more restrictive state-wide policy providing emergency shelter for families, but not homeless individuals, who meet certain requirements, including for families who are homeless due to health conditions. ${ }^{22}$ Supportive housing has been associated not only with reductions in inpatient and emergency room visits, ${ }^{28}$ but also with overall improvements in health for homeless individuals. ${ }^{29}$ Such policies therefore may also lead to a reduction in hospital readmissions.

Since we analyzed a substantially larger number of hospitalizations of homeless individuals compared with prior investigations, we were also able to evaluate if readmission rates varied by cause index admissions. Although the burden of mental illness among people who experience homelessness is well documented, our study shows that pregnancy-related care, cardiovascular disease, and gastrointestinal diseases are also major causes of readmissions in this population. Notably, the differences in readmission rates between hospitalizations for homeless and housed individuals were largest for hospitalizations related to cardiovascular diseases and smallest for pregnancy-related hospitalizations. Although our study was not designed to elucidate the mechanisms underlying the higher readmission rates among individuals experiencing homelessness, some of this disparity may due to differences in certain cardiovascular risk factors such as higher rates of tobacco use among homeless individuals. A plausible explanation is that people who experience homelessness may be particularly vulnerable to readmissions after an index hospitalization for chronic diseases, such as those of the cardiovascular system, where early post-discharge follow-up, coordinated outpatient care, and medication adherence may be critical to avoiding readmissions. ${ }^{30,} 31$ These findings contrast with those of our prior work that did not show differences in inpatient mortality rates associated with homelessness. ${ }^{11}$ Taken together, these findings suggest that while homeless individuals may achieve similar outcomes as housed patients during a hospital admission, they are particularly vulnerable after discharge from the hospital.

Our findings have major implications for safety net hospitals that tend to provide a disproportionate share of care to homeless and other socially disadvantaged individuals. Hospital-level readmission rates are increasingly being used to evaluate the quality of care under value-based payment 
programs, including the Hospital Readmissions Reduction Program (HRRP), which levies financial penalties on hospitals based on their performance. Surveys of leadership of safety net hospitals consistently point to homelessness as a major factor that increases the risk of hospital readmissions, ${ }^{32,33}$ in concordance with our finding of higher readmission rates among homeless patients. Despite this, HRRP does not adequately capture homelessness as a social risk factor in risk-adjustment algorithms, and as a result, hospitals that provide care to a significant number of homeless individuals are likely particularly vulnerable to financial penalties. ${ }^{11}$ Our study highlights the need for value-based programs to evaluate homelessness in risk-adjustment algorithms in order to ensure fair comparisons of hospital performance, and to protect often resource-poor hospitals from being disproportionately penalized for serving this vulnerable population.

\section{Limitations}

Our analysis was limited to three states and the findings may not be generalizable beyond these states. However, to our knowledge, this is the first study to assess readmission rates across multiple states that collectively account for more than a quarter of all homeless individuals in the USA. Available data dictated that homelessness in this analysis was defined as being designated homeless at the time of discharge from the index hospitalization. This likely represents a more "sensitive" measure of homelessness as it includes all individuals who are homeless at the time of discharge regardless of their subsequent housing status after discharge. We were unable to directly examine the effect of duration of homelessness or availability of temporary housing. Additionally, as SID data is reported by individual hospitals, there could be possible misclassification of homeless individuals at the time of discharge. If the misclassification is systemic and varies specifically by state, then this may bias the overall results depending on the direction of the misclassification. However, as the classification is performed at the individual hospital level, and there is no specific evidence suggesting differential misclassification, this is likely to bias the results towards the null and the estimates are likely conservative. We defined readmissions as rehospitalizations that occurred within 30 or 90 days of the index hospitalization and any subsequent hospitalizations were classified as a new index hospitalization. This does not account for certain individuals who may be readmitted multiple times before and after each time threshold. For individuals where mental illness was not the cause of index hospitalization, we were unable to adjust for mental illness comorbidities as this was not collected by all of the states included in the analysis. However, given that the disparity in readmissions exists even for individuals where mental illness was the cause of index hospitalization, this suggests that the direction of the association is likely not affected by lack of this adjustment.

\section{Conclusion}

Homelessness at the time of discharge is associated with significantly higher rates of 30- and 90-day readmission rates in the states of Florida, Massachusetts, and New York during 2010 to 2015 , with a significant variation across the three states and by cause of index hospitalization. Effective and scalable interventions targeted towards the post-discharge period are urgently needed to address the disparities observed in our study.

Corresponding Author: Sameed Ahmed M. Khatana, MD, MPH; Division of Cardiovascular Medicine, Perelman School of Medicine, University of Pennsylvania, 3400 Civic Center Boulevard, Philadelphia, PA 19104-5162, USA (e-mail: sameed.khatana@pennmedicine. upenn.edu).

Funding Information Dr. Khatana's work is supported by funding from the National Heart, Lung, and Blood Institute (NHLBI) (5T32HLOO7843).

\section{Compliance with Ethical Standards:}

Conflict of Interest: The authors declare that they do not have a conflict of interest.

Disclaimer: The funding source had no role in this study.

\section{REFERENCES}

1. Henry M, Mahathey A, Morrill T, Shivji A, Watt R, Abt Associates. The 2018 Annual Homeless Assessment Report (AHAR) to Congress, Part 1: Point-in-Time Estimates of Homelessness - 2018-AHAR-Part-1.pdf: The U.S. Department of Housing and Urban Development Office of Community Planning and Development2018.

2. Tsai J. Lifetime and 1-year prevalence of homelessness in the US population: results from the National Epidemiologic Survey on Alcohol and Related Conditions-III. J. Public Health. 2018;40(1):65-74. doi:https://doi.org/10.1093/pubmed/fdx034

3. Fazel S, Geddes JR, Kushel M. The health of homeless people in highincome countries: descriptive epidemiology, health consequences, and clinical and policy recommendations. Lancet. 2014;384(9953): 1529-40. doi:https://doi.org/10.1016/S0140-6736(14)61132-6

4. Szerlip MI, Szerlip HM. Identification of cardiovascular risk factors in homeless adults. Am. J. Med. Sci. 2002;324(5):243-6.

5. Fazel S, Khosla V, Doll H, Geddes J. The prevalence of mental disorders among the homeless in western countries: systematic review and metaregression analysis. PLoS Med. 2008;5(12):e225. doi:https://doi.org/10. 1371/journal.pmed.0050225

6. Baggett TP, O'Connell JJ, Singer DE, Rigotti NA. The unmet health care needs of homeless adults: a national study. Am. J. Public Health. 2010;100(7):1326-33. doi:https://doi.org/10.2105/AJPH.2009.180109

7. Kushel MB, Gupta R, Gee L, Haas JS. Housing instability and food insecurity as barriers to health care among low-income Americans. J. Gen. Intern. Med. 2006;21(1):71-7. doi:https://doi.org/10.1111/j.15251497.2005.00278.x

8. Kushel M. Homelessness: A Potent Risk Factor for Readmission. Med. Care. 2018;56(6):457-9. doi:https://doi.org/10.1097/MLR. 0000000000000920

9. Lucas DS. The Impact of Federal Homelessness Funding on Homelessness. Southern Economic Journal. 2017;84(2):548-76. doi:https://doi. org/10.1002/soej.12231 
10. Kushel MB. Factors Associated With the Health Care Utilization of Homeless Persons. JAMA. 2001;285(2):200. doi:https://doi.org/10. $1001 /$ jama.285.2.200

11. Wadhera RK, Choi E, Shen C, Yeh RW, Joynt Maddox KE. Trends, Causes, and Outcomes of Hospitalizations for Homeless Individuals: A Retrospective Cohort Study. Med. Care. 2019;57(1):21-7. doi:https://doi. org/10.1097/MLR.0000000000001015

12. Saab D, Nisenbaum R, Dhalla I, Hwang Sw. Hospital Readmissions in a Community-based Sample of Homeless Adults: a Matched-cohort Study. Journal of General Internal Medicine. 2016;31(9):1011-8. doi:https:// doi.org/10.1007/s11606-016-3680-8

13. Buck DS, Brown CA, Mortensen K, Riggs JW, Franzini L. Comparing Homeless and Domiciled Patients' Utilization of the Harris County, Texas Public Hospital System. Journal of Health Care for the Poor and Underserved. 2012;23(4):1660-70. doi:https://doi.org/10.1353/hpu. 2012.0171

14. Titan A, Graham L, Rosen A, Itani K, Copeland LA, Mull HJ, et al. Homeless Status, Postdischarge Health Care Utilization, and Readmission After Surgery. Med. Care. 2018;56(6):460-9. doi:https://doi.org/10. 1097/MLR.0000000000000915

15. Joynt KE, Jha AK. Characteristics of hospitals receiving penalties under the Hospital Readmissions Reduction Program. JAMA. 2013;309(4):3423. doi:https://doi.org/10.1001/jama.2012.94856

16. Henry M, Shivji A, de Sousa T, Cohen R. The 2015 Annual Homeless Assessment Report (AHAR) to Congress: Part 1: Point-In-Time (PIT) Estimates of Homelessness2015 November.

17. HCUP State Inpatient Databases (SID). Healthcare Cost and Utilization Project (HCUP). 2010-2015. Agency for Healthcare Research and Quality, Rockville, MD. www.hcup-us.ahrq.gov/sidoverview.jsp. .

18. Sun R, Karaca Z, Wong HS. Characteristics of Homeless Individuals Using Emergency Department Services in 2014: Statistical Brief \#229. Healthcare Cost and Utilization Project (HCUP) Statistical Briefs. Rockville (MD): Agency for Healthcare Research and Quality (US); 2017.

19. White BM, Ellis C, Jr., Simpson KN. Preventable hospital admissions among the homeless in California: a retrospective analysis of care for ambulatory care sensitive conditions. BMC Health Serv. Res. 2014;14:511. doi:https://doi.org/10.1186/s12913-014-0511-7

20. Manzano-Nunez R, Zogg CK, Bhulani N, McCarty JC, Herrera-Escobar JP, Lu K, et al. Association of Medicaid Expansion Policy with Outcomes in Homeless Patients Requiring Emergency General Surgery. World J. Surg. 2019;43(6):1483-9. doi:https://doi.org/10.1007/s00268-01904932-0

21. White B, Ellis C, Jones W, Moran W, Simpson K. The effect of the global financial crisis on preventable hospitalizations among the homeless in New York State. J. Health Serv. Res. Policy. 2018;23(2):80-6. doi:https://

\section{doi.org/10.1177/1355819617742180}

22. Eligibility for emergency assistance (EA). Massachusetts Department of Housing and Community Development., (2009/07/01, 2009).

23. Elixhauser A, Steiner C, Harris DR, Coffey RM. Comorbidity measures for use with administrative data. Med Care. 1998;36(1):8-27. doi:https:// doi.org/10.1097/00005650-199801000-00004

24. Status of State Action on the Medicaid Expansion Decision. Kaiser Family Foundation. 2019. https://www.kff.org/health-reform/state-indicator/ state-activity-around-expanding-medicaid-under-the-affordable-careact/. Accessed September 12019.

25. Parker RD, Cima MJ, Brown Z, Regier M. Expanded Medicaid Provides Access to Substance Use, Mental Health, and Physician Visits to Homeless and Precariously Housed Persons. J Community Health. 2018;43(2):207-11. doi:https://doi.org/10.1007/s10900-017-0405-9

26. U. S. Department of Housing and Urban Development. 2007-2018 Pointin-Time Counts by State. https://www.hudexchange.info/resources/ documents/2007-2018-PIT-Counts-by-State.xlsx. 2019.

27. NYC Department of Homeless Services. https://wwwl.nyc.gov/site/dhs/ shelter/shelter.page. Accessed July 32019.

28. Hunter SB, Harvey M, Briscombe B, Cefalu M. Housing for Health: RAND Corporation2017.

29. Buchanan D, Kee R, Sadowski LS, Garcia D. The health impact of supportive housing for HIV-positive homeless patients: a randomized controlled trial. Am J Public Health. 2009;99 Suppl 3:S675-80. doi:https://doi.org/10.2105/AJPH.2008.137810

30. Hernandez AF, Greiner MA, Fonarow GC, Hammill BG, Heidenreich PA, Yancy CW, et al. Relationship between early physician follow-up and 30-day readmission among Medicare beneficiaries hospitalized for heart failure. JAMA. 2010;303(17):1716-22. doi:https://doi.org/10.1001/ jama.2010.533

31. Ruppar TM, Cooper PS, Mehr DR, Delgado JM, Dunbar-Jacob JM. Medication Adherence Interventions Improve Heart Failure Mortality and Readmission Rates: Systematic Review and Meta-Analysis of Controlled Trials. Journal of the American Heart Association. 2016;5(6). https://doi. org/10.1161/jaha.115.002606

32. Figueroa JF, Joynt KE, Zhou X, Orav EJ, Jha AK. Safety-net Hospitals Face More Barriers Yet Use Fewer Strategies to Reduce Readmissions. Med. Care. 2017;55(3):229-35. doi:https://doi.org/10.1097/MLR. 0000000000000687

33. Siegel B. Reducing Readmissions in Safety Net Hospitals \& Health Systems. 2011.

Publisher's Note: Springer Nature remains neutral with regard to jurisdictional claims in published maps and institutional affiliations. 